\title{
FORMAÇÃO CONTÍNUA NA INDÚSTRIA DA CONSTRUÇÃO: A METODOLOGIA BIM
}

\author{
Alcínia Zita Sampaio \\ Universidade de Lisboa, Instituto Superior Técnico, Departamento de Engenharia Civil, Arquitectura e Georrecursos \\ Av. Rovisco Pais 1049-001 Lisboa, Portugal
}

\begin{abstract}
RESUMO
A demonstração dos benefícios inerentes ao recurso à metodologia Building Information Modelling (BIM) na indústria da Construção, registada no desenvolvimento de diversas actividades assentes no projecto, motiva o grande interesse, que se tem recentemente verificado por projectistas e gestores, em conhecer o seu conceito e a abrangência da sua aplicabilidade. A metodologia assenta nos avanços tecnológicos alcançados e no nível de interoperabilidade estabelecida entre ferramentas de base BIM, apoiando o desenvolvimento de projectos colaborativos e centralizados. A escola tem acompanhado este interesse, introduzindo alterações curriculares, essencialmente ao nível do último grau de estudos, mas também na organização de cursos de curta duração, oferecidos aos profissionais da indústria. Assim a acção de formação contínua oferecida pela escola tem incluído, recentemente, cursos sobre a temática BIM abrangendo diversos aspectos, desde o conceito de modelação paramétrica até à análise da capacidade de interoperabilidade. $\mathrm{O}$ texto apresenta a organização de cursos profissionais no âmbito BIM. Os cursos pretendem contribuir para a divulgação das potencialidades da implementação da metodologia BIM em sectores como infra-estruturas, planeamento da construção, análise de conflitos ou dimensionamento estrutural e são dirigidos aos diversos sectores da indústria da Construção. O grau de satisfação manifestado pelos participantes é analisado e confrontado com as suas espectativas e interesse nos cursos.
\end{abstract}

\section{PALAVRAS-CHAVE}

BIM, Formação, Actualização Profissional, Curso Profissional, BIM na Indústria

\section{INTRODUÇÃO}

A metodologia Building Information Modelling (BIM) é actualmente a principal plataforma de trabalho na indústria da Construção, e todos os sectores têm vindo a potenciar a sua aplicabilidade. O conceito BIM assenta na geração de um modelo digital centralizado de toda a informação relacionada com a construção (Eastman, 2011). O modelo geométrico, inicialmente bastante atractivo e identificador do conceito básico do BIM, evoluiu para a sua real capacidade, apoiando a realização de todas as tarefas envolvidas na concepção, construção e gestão de um edifício ou infra-estrutura (Eadie, 2013). Actualmente, o BIM está implementado na Construção, nomeadamente entre arquitectos, engenheiros, coordenadores e gestores, contribuindo positivamente para a integração das diferentes especialidades e apoiando a tomada de decisão, em período prévio à construção, e de um modo sustentado, por consulta da informação acedida a partir do modelo (Chen $\&$ Luo, 2014).

O modelo é criado, acrescentado e actualizado durante toda a vida útil do edifício, e a informação que armazena pode ser consultada e utilizada na elaboração das distintas tarefas que são usualmente definidas sobre a documentação gráfica e escrita do projecto (Sampaio, 2018). O BIM pode ser definido como uma representação digital do edifício ou infra-estrutura, contendo toda a informação necessária à sua construção e gestão, fortemente apoiada na modelação paramétrica e na padronização, como base de transferência de dados entre especialidades: O projecto de estruturas, elaborado no âmbito da metodologia BIM, depende da capacidade de interoperabilidade entre as ferramentas BIM e os sistemas de análise estrutural; a informação do modelo 3D de arquitectura, estruturas ou geotecnia, pode ser manipulada de forma a permitir a criação de modelos 4D (com a adição do parâmetro tempo no planeamento da construção) ou de modelos 5D (incluindo a extracção de quantidades de material e a estimativa de custos). A aplicação do conceito BIM requer a utilização de ferramentas com capacidades avançadas de modelação geométrica e de um elevado nível de 
interoperabilidade requerido no apoio ao desenvolvimento das múltiplas tarefas assentes no projecto. As potencialidades actuais da aplicação da metodologia BIM abrangem assim todos os sectores da indústria da Construção (Sampaio, 2017).

A implementação do BIM é apoiada a um nível governamental e num âmbito internacional, incentivando os profissionais de construção a adoptarem a metodologia, o que conduz naturalmente à procura de acções de formação que lhes possam acrescentar conhecimento no contexto BIM, requerido na sua actividade (Sampaio, 2019). Nesse sentido as escolas técnicas têm vindo a adaptar os seus programas curriculares de forma a incluir a temática BIM. Têm igualmente organizado cursos de formação profissional, onde são ministrados os conceitos e apresentando um leque alargado da aplicabilidade inerente ao desenvolvimento de projectos em ambiente BIM, de acordo com a exigência manifestada pela indústria. A indústria e a escola devem ser parceiros na procura da melhor estratégia para o estabelecimento de modos eficazes de ensino úteis à comunidade. $\mathrm{O}$ presente texto aborda a organização e os conteúdos e, ainda, a avaliação, por parte dos participantes, de um dos últimos cursos de formação contínua, sobre o BIM, apresentado na Universidade de Lisboa.

\section{CURSOS DE FORMAÇÃO CONTÍNUA}

A Associação para a Formação e o Desenvolvimento em Engenharia Civil e Arquitectura (FUNDEC) resultou da corporação entre o Departamento de Engenharia Civil, Arquitectura e Georrecursos (DECivil) do Instituto Superior Técnico (IST) e empresas nacionais na área da Engenharia Civil. Esta iniciativa foi pioneira na parceria Universidade/Empresas no sector económico da Construção (FUNDEC, 2019). Os cursos de especialização pretendem abranger todas as áreas de especialização do domínio alargado da Engenharia Civil e destinam-se a suprir, actualizar e requalificar a formação das pessoas através da inovação de matérias e conteúdos de modo a assegurar uma real valorização profissional.

Estes cursos são leccionados nas instalações da FUNDEC localizadas no DECivil do IST. No âmbito BIM, os cursos oferecidos pela FUNDEC apresentam diversas utilizações do modelo BIM no apoio: ao planeamento e à gestão da construção de edifícios e infra-estruturas; à quantificação de material do projecto; ao dimensionamento estrutural; à organização da obra geotécnica. Com base na apresentação de estudos e situações reais são identificados os principais benefícios e limitações na geração e utilização do modelo BIM. Os cursos, organizados com uma duração de dia laboral, são dirigidos aos diversos níveis e sectores da indústria. Os cursos têm sido ministrados desde 2011 com uma periodicidade trianual. A afluência aos cursos tem vindo a aumentar recentemente, denotando um maior interesse na actualização profissional com o BIM. A procura é diversificada abrangendo arquitectos, engenheiros civis e mecânicos, desenhadores e gestores. Mais recentemente têm-se verificado que os participantes ocupam, nas suas empresas, funções de chefia, revelando um maior consciencialização de que esta temática deve ser implementada nas empresas que dirigem, avaliando assim qual o impacto que a implementação da metodologia terá na sua actividade.

O curso mais recente, ministrado em Junho de 2019, "A metodologia BIM na indústria da Construção", apresenta um programa com uma componente prática e outra mais teórica (Curso FUNDEC, 2019). Previamente ao estabelecimento concreto do programa, as empresas interessadas manifestaram vantagem na aprendizagem prática do uso de ferramenta de base BIM. O curso inclui assim uma introdução à metodologia, a manipulação de uma ferramenta de BIM tendo como base o conceito da modelação paramétrica, seguindo-se um leque diversificado demonstrativo da aplicabilidade do BIM:

- Building Information Modelling (BIM): Definição, estado-de-arte, aplicação, benefícios e limitações; modelação paramétrica e capacidade de interoperabilidade; conceito de multiutilização da informação do modelo BIM.

- $\quad$ Prática de utilização de ferramenta de base BIM: Definições iniciais, níveis dos pisos e grelha de alinhamentos; geração de modelo paramétrico 3D/BIM; representação 2D e 3D e obtenção de tabelas de quantidades.

- A metodologia BIM no projecto de estruturas: Modelação e análise de interoperabilidade.

- $\quad$ O modelo 4D/BIM como suporte ao planeamento da construção: Sistemas BIM de modelação e de visualização; monitorização do processo construtivo.

- Aplicação da metodologia BIM em infra-estruturas: Ilustração de casos reais de barragens e rodovias. 
- Geração, actualização e aplicação de objectos paramétricos: Selecção de parâmetros específicos e estudo de soluções alternativas.

- Detecção de conflitos no projecto de serviços: Sobreposição de especialidades.

\subsection{Componente Prática}

De forma a introduzir, no âmbito do curso, a aprendizagem na utilização de ferramentas de base BIM, é criada a componente de arquitectura do modelo BIM, relativa a uma vivenda unifamiliar. A Figura 1 ilustra os desenhos utilizados como base à modelação. O primeiro passo, no processo da geração do modelo BIM, é seleccionar, na interface inicial do sistema BIM, disponibilizado para todos os participantes, o menu Arquitectura. É criado um novo projecto e são estabelecidas as configurações de base pretendidas, como as unidades de trabalho, o número de níveis de elevação do edifício (designação e cota) e os alinhamentos de suporte à modelação de elementos verticais.

A modelação BIM é baseada na utilização de objectos paramétricos com características geométricas e propriedades físicas associadas. Cada objecto é referido a uma tipologia (parede ou laje com espessuras e materiais específicos) e é garantido o estabelecimento de relações de interligação entre elementos. O modelo BIM de arquitectura é iniciado pela inserção de paredes, seguindo-se a colocação de janelas, portas, pavimentos, cobertura e, ainda, outros elementos arquitectónicos (Figura 1).

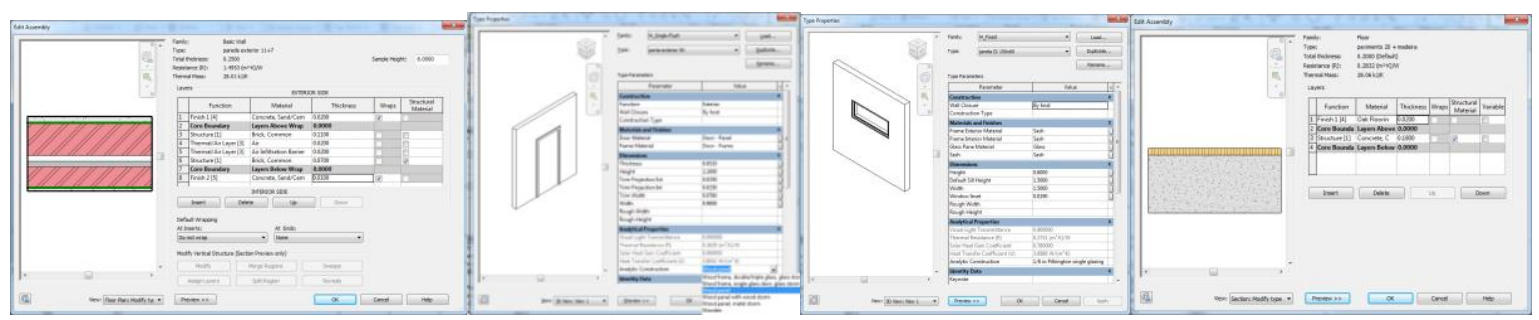

Figura 1. Objectos paramétricos de paredes, janelas, portas e pavimentos

No processo de modelação, a vista de trabalho a considerar deve ser uma planta de piso. As restrições à sua altura são indicadas através da selecção do nível inferior e superior dos pisos criados e o alinhamento segue a grelha pré-definida. Embora o processo de modelação de paredes, seja mais facilmente executado sobre a vista em planta, o procedimento corresponde à criação de um modelo tridimensional (3D). Assim, é possível obter uma projecção do modelo 3D criado, através das capacidades de visualização disponibilizadas no sistema. Posteriormente, são seleccionados na biblioteca de objectos do sistema, os elementos de pavimento, grade e cobertura (Figura 2).

De forma a introduzir o conceito de extracção de informação do modelo para a obtenção e o suporte ao desenvolvimento de várias actividades capazes de serem elaboradas sobre o modelo criado, é ilustrada a obtenção automática de desenhos, cortes em perspectiva e tabelas de quantidades (Figura 3).
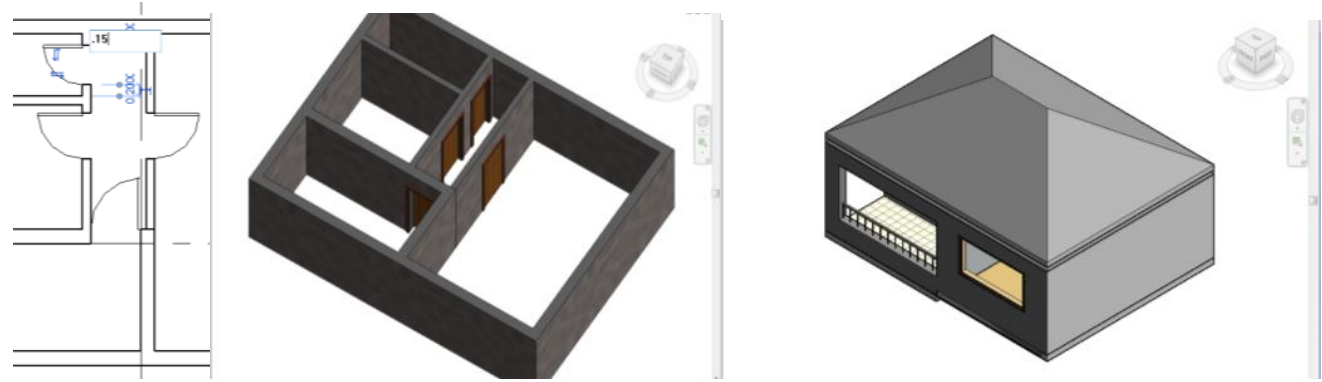

Figura 2. Geração e visualização do modelo BIM criado 


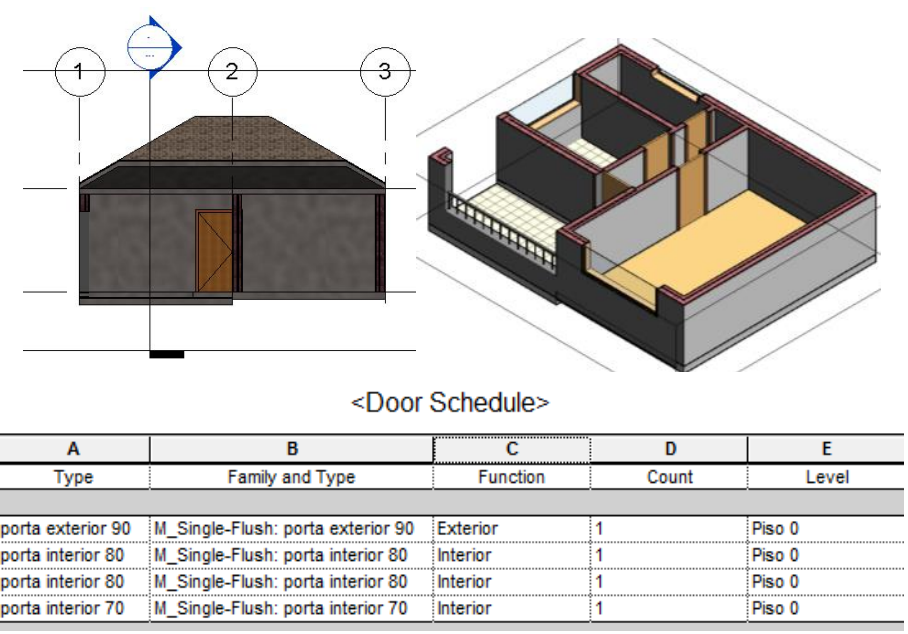

Figura 3. Representação de cortes aplicados sobre vistas e perspectiva e definição de tabela de quantidades

\subsection{Aplicabilidade do BIM}

Introduzidos os conceitos básicos relativos ao uso de uma ferramenta de modelação BIM e a essência da definição e utilização de objectos paramétricos, são apresentados alguns aspectos mais avançados de aplicação da metodologia BIM: projecto de estruturas, planeamento da construção, infra-estruturas, objectos paramétricos específicos e detecção de conflitos:

- No âmbito do desenvolvimento de um projecto de estruturas, em ambiente BIM, é apresentado um caso real incluindo: o estabelecimento de uma solução estrutural, em betão armado, definida sobre a arquitectura; o procedimento relativo ao dimensionamento estrutural; a pormenorização de armaduras. O processo requer a utilização de ferramenta de modelação (arquitectura e estruturas), a transferência de modelos entre os softwares de modelação e de cálculo e, finalmente, a transferência da pormenorização de armaduras, para o modelo BIM inicial, actualizando-o com a informação da especialidade de estruturas (Figura 4). A capacidade de interoperabilidade verificada entre os sistemas de base BIM utilizados no processo é analisada, de forma a identificar os principais benefícios e limitações (Sampaio \& Oliveira, 2019).
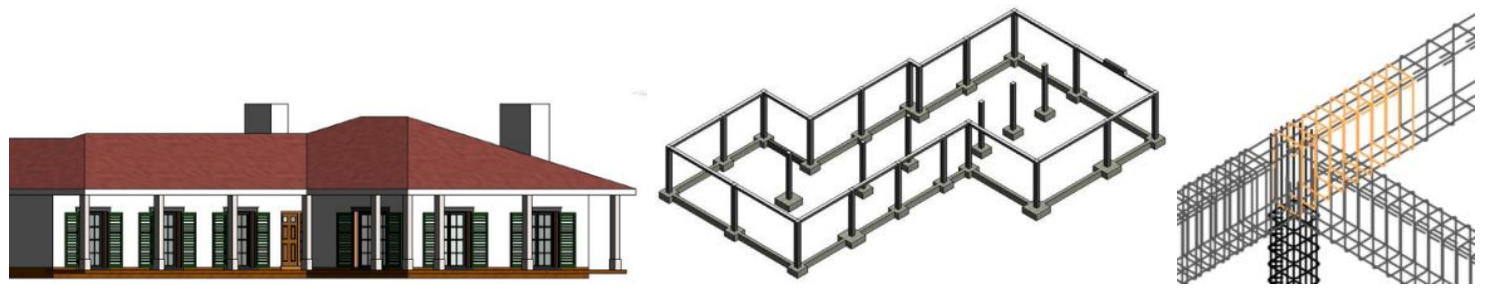

Figura 4. Geração das componentes de arquitectura e de estruturas e pormenorização de armaduras

- $\quad$ O BIM apoia o planeamento da construção através da elaboração do modelo 4D (3D + tempo). O caso concreto apresentado ilustra o procedimento de modelação das componentes de arquitectura e de estruturas de um edifício, o planeamento de tarefas estabelecido para sua construção (mapa de Gantt) e a transposição dos modelos e do planeamento para um visualizador BIM. Neste sistema é elaborado o respectivo modelo 4D da construção, de forma a poder simular a actividade construtiva e apoiar a monitorização da obra (Figura 5). É identificado o procedimento mais adequado no agrupamento de componentes de construção e a sua associação à respectiva tarefa, incluída no mapa de Gantt. É ainda ensinado como o modelo 4D pode ser actualizado, em função das alterações à sequência construtiva, as quais ocorrerem frequentemente numa obra real (Sampaio \&Mota, 2016). 


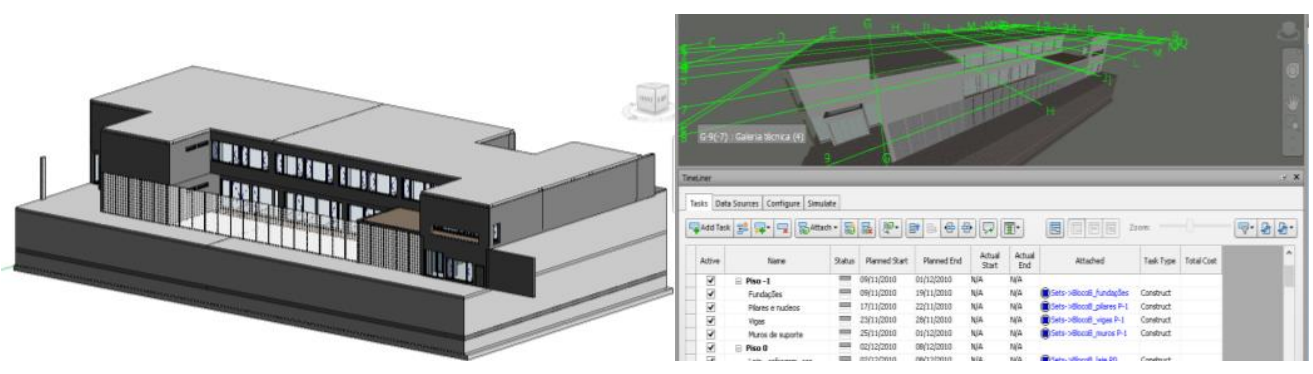

Figura 5. Elaboração e utilização do modelo 4D/BIM

- Embora a metodologia BIM esteja mais implementada na construção de edifícios, começa a ser reconhecida a sua aplicabilidade em infra-estruturas, onde se verificam benefícios importantes mas também muitas limitações, baseadas essencialmente na não existência de objectos paramétricos específicos de rodovias, ferrovias ou componentes de barragem, nas bibliotecas de objectos, disponibilizados nos sistemas de modelação BIM de uso mais frequente. Assim, este ponto é ilustrado com situações concretas em que são definidas estratégias de adaptação de modelos geométricos, na concepção de modelos com alguma componente BIM (Figura 6). As limitações são identificadas e é referido o sentido da presente investigação, por parte das casas de software, numa perspectiva de contribuírem para a implementação do BIM com êxito, também, neste sector (Serra, 2019).

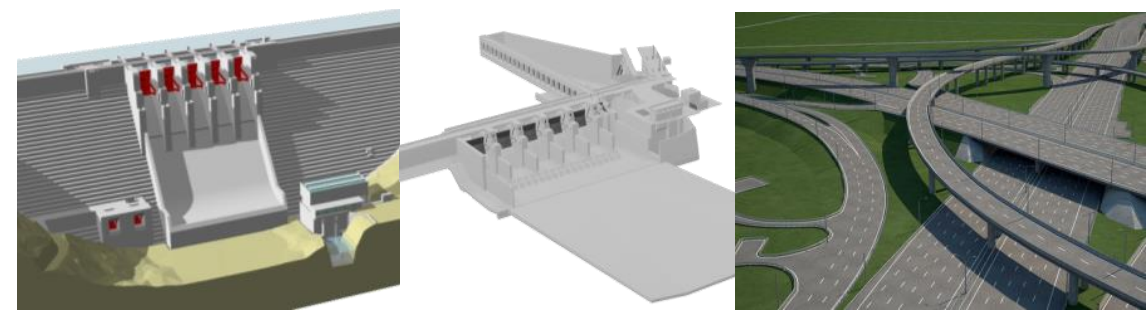

Figura 6. Implementação do BIM em infra-estruturas

- No sentido de se poderem analisar soluções alternativas num projecto de arquitectura, é necessária a geração de uma biblioteca de objectos paramétricos com as características das componentes construtivas que se pretendam estudar. Assim em relação a paredes exteriores, foi inicialmente identificado um conjunto de tipos frequentemente aplicados na construção tradicional, foram gerados os respectivos objectos paramétricos e introduzidos os parâmetros complementares necessários. Construído um modelo arquitectónico de base, foram de seguida alteradas as paredes exteriores, de forma a estabelecer soluções alternativas, e efectuado distinto tipo de análise de sustentabilidade (Figura 7). O aspecto visual é o mais evidente, mas o conforto acústico e térmico ou os custos de construção e de manutenção, podem igualmente ser analisados e comparados entre as soluções. Para tal, são utilizados os valores associados aos parâmetros específicos adicionados. O caso concreto apresentado ilustra como criar, utilizar e actualizar os objectos paramétricos em função dos objectivos pretendidos com a elaboração do projecto em ambiente BIM (Araújo, 2016).

- Finalmente, o aspecto de sobreposição de especialidades (arquitectura, estruturas e sistemas) tem vindo a ser demonstrado, recentemente, que pode ser fortemente apoiado pelo recurso às capacidades de detecção de conflitos, proporcionadas pelas ferramentas de base BIM. Através de situações concretas de modelação e de sobreposição de especialidades, são identificadas as intersecções verificadas entre elementos de diferentes disciplinas, as quais são facilmente corrigidas na ferramenta de modelação. Esta capacidade apoia o projectista de redes prediais, de telecomunicações ou de ar condicionado, na definição do projecto da sua especialidade de forma a ser adequadamente acomodado no edifício (Sampaio \& Berdeja, 2017). 


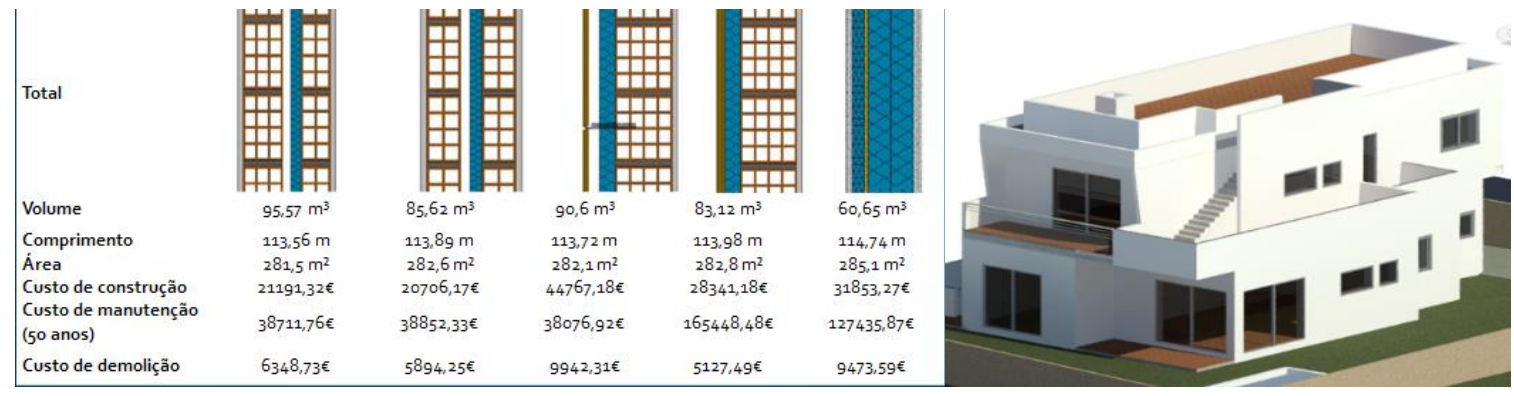

Figura 7. Geração e aplicação de objectos paramétricos de paredes exteriores

\subsection{Avaliação do Curso}

O curso promove, assim, uma aprendizagem do conceito BIM e a utilização de ferramentas e, adicionalmente, aborda a sua aplicabilidade, orientada para os aspectos mais relevantes e de interesse na profissão na Construção, atendendo aos requisitos e espectativas dos participantes. A maioria dos assistentes não tem qualquer conhecimento da metodologia, mas reconhecem, pela própria exigência competitiva do sector, que o BIM é um conhecimento que devem adquirir. A componente prática do curso é inserida como base à introdução da real capacidade da metodologia, estendida à extracção de informação e ao uso de ferramentas BIM complementares e específicos (cálculo estrutural ou visualizadores). A documentação entregue aos participantes, consiste num texto em formato tutorial, referente à componente prática do curso, e um conjunto de slides organizados por cada formador.

Concluído o curso de formação, os participantes são convidados a responderem a um pequeno inquérito permitindo transmitir ao coordenador a aos formadores, qual a satisfação perante as expectativas iniciais e qual a direcção de orientação que futuros cursos poderão seguir de forma a melhor responder às exigências da comunidade (Tabela 1). O tratamento estatístico foi fornecido pela FUNDEC ilustrando de uma forma quantitativa a qualidade do curso e as preferências dos tópicos abordados, segundo a perspectiva dos participantes.

Naturalmente que o curso, ministrado a uma assistência heterogénea de formação, satisfaz de um modo distinto as espectativas que os participantes tinham inicialmente com o curso. No entanto, a apreciação global é muito satisfatória e verifica-se que os temas que mais agradaram estão relacionados com a componente prática, as infra-estruturas, a detecção de conflitos e os objectos paramétricos. De acordo com as sugestões relativas a tópicos a abordar futuramente, é intenção da coordenação incluir uma componente mais prática de utilização, de ferramentas BIM, não só de modelação mas também de apoio à análise de interferências, de planeamento de construção ou mesmo de cálculo estrutural. A sua duração deverá contudo ser maior, prevendo-se o planeamento de cursos com dois dias. A procura deste tipo de cursos é cada vez maior, nomeadamente por parte de Câmaras Municipais e por instituições públicas, revelando que começa a haver um reconhecimento, a um nível público, de que a implementação obrigatória do BIM, que segundo a Comissão Técnica (CT) 197 (Normalização BIM) (2017) deverá ocorrer em breve, e que há semelhança de outros países a imposição é governamental. As instituições públicas devem assim estar actualizadas com esta componente. 
Tabela 1. Avaliação de satisfação com o curso ministrado

\begin{tabular}{|c|c|c|}
\hline Tópicos & Comentários & Qualidade \\
\hline Apreciação global & $\begin{array}{l}\text { - O curso de formação excedeu as expectativas tendo } \\
\text { em conta o tempo disponível, permitindo obter uma } \\
\text { perspectiva global do BIM e da sua aplicabilidade. } \\
\text { - Tempo de formação insuficiente, pois o curso requer } \\
\text { uma maior duração, com uma componente prática } \\
\text { mais demorada e especifica. } \\
\text { - Documentação reduzida face à abrangência do BIM. }\end{array}$ & 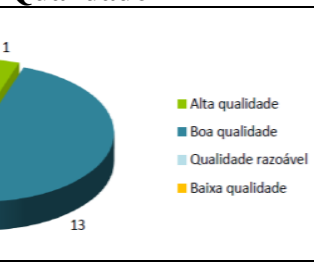 \\
\hline $\begin{array}{c}\text { Introdução ao BIM } \\
\text { e sessão prática }\end{array}$ & $\begin{array}{l}\text { - Importante inserção de componente prática na } \\
\text { formação, permitindo aprendizagem de fundamentos } \\
\text { da utilização de ferramenta de base BIM. } \\
\text { - Formador muito prático, pragmático e disponível e } \\
\text { desempenhou bem a função de coordenador do } \\
\text { curso. } \\
\text { - Fácil empatia com os formandos e resposta } \\
\text { inteligente e acessível às questões colocadas. } \\
\text { - Faltou apoio informático na sessão prática e o caso } \\
\text { prático requer mais tempo. }\end{array}$ & $\begin{array}{l}\text { —Alta qualidade } \\
\text { —Boa qualidade } \\
\text { Qualidade razoável } \\
\text { "Baixa qualidade }\end{array}$ \\
\hline $\begin{array}{l}\text { Projecto de } \\
\text { estruturas }\end{array}$ & $\begin{array}{l}\text { - Desenvolvimento de projecto de estruturas } \\
\text { demonstrado em todas as etapas de modelação e } \\
\text { transferência de dados. } \\
\text { - Formador com boa capacidade de comunicação e } \\
\text { transmissão dos assuntos e soube responder às } \\
\text { questões colocadas. }\end{array}$ & $\begin{array}{l}\text { = Alta qualidade } \\
\text { "Boa qualidade } \\
\text { " Oualildade razodvel } \\
=\text { Baixa qualidade }\end{array}$ \\
\hline $\begin{array}{l}\text { Planeamento da } \\
\text { construção }\end{array}$ & $\begin{array}{l}\text { - Dentro do tempo disponível foi apresentada a } \\
\text { capacidade de simulação de construção, com a } \\
\text { transmissão do básico possibilitando futuramente um } \\
\text { estudo mais aprofundado. } \\
\text { - Formador muito expedito na explicação e disponível } \\
\text { para esclarecer questões de forma adequada, } \\
\text { conseguindo apresentar as vantagens de utilização. }\end{array}$ & 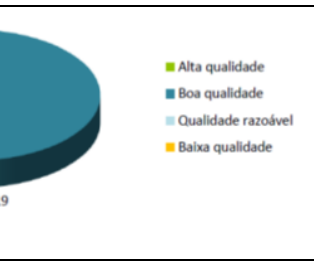 \\
\hline Infra-estruturas & $\begin{array}{l}\text { - Demonstração da aplicabilidade do BIM na rodovia } \\
\text { e barragens, embora sem conteúdo técnico mas } \\
\text { generalista e útil. } \\
\text { - Formador prático, explícito nos temas abordados, } \\
\text { boa capacidade de transmissão da informação e } \\
\text { soube responder às questões colocadas. }\end{array}$ & $\begin{array}{l}\text { W Alta qualidade } \\
\text { — Boa qualidade } \\
\text { — Qualldade razoóvel } \\
\text { W Baixa qualidade }\end{array}$ \\
\hline $\begin{array}{c}\text { Objectos } \\
\text { paramétricos }\end{array}$ & $\begin{array}{l}\text { - Exposição interessante e bem estruturada de } \\
\text { exemplo prático de utilização de software e da } \\
\text { aplicação do BIM. } \\
\text { - Demonstração de potencialidades do software e suas } \\
\text { limitações, bem ilustrada com exemplos adequados. }\end{array}$ & 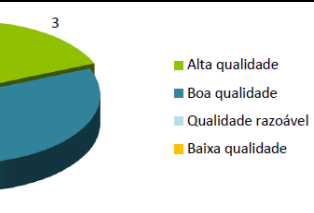 \\
\hline Detecção conflitos & $\begin{array}{l}\text { - Caso de interesse de aplicação muito prática na } \\
\text { actividade do projectista coordenador. } \\
\text { - O formador expressa-se com clareza e denota bons } \\
\text { conhecimentos teóricos e práticos. }\end{array}$ & 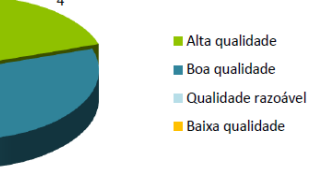 \\
\hline $\begin{array}{l}\text { Sugestão de tópicos } \\
\text { a incluir em cursos } \\
\text { BIM }\end{array}$ & $\begin{array}{l}\text { - Curso prático de BIM. } \\
\text { - BIM aplicado a obras subterrâneas. } \\
\text { - Exploração da metodologia BIM na gestão e } \\
\text { coordenação. } \\
\text { - Cursos práticos de outros softwares de base BIM. } \\
\text { - Padronização e parametrização de objectos } \\
\text { construtivos; } \\
\text { - Caracterização dos modelos BIM 5D/6D/7D e 8D. }\end{array}$ & \\
\hline
\end{tabular}




\section{CONCLUSÕES}

O conteúdo programático do curso profissional, no âmbito da temática BIM e oferecido pela FUNDEC, foi organizado de forma a adaptar-se às solicitações requeridas pela indústria, mas de forma a abranger um vasto leque da aplicabilidade do BIM no sector. Os participantes revelaram bastante interesse em todos os tópicos apresentados, questionando frequentemente os formadores, numa perspectiva de esclarecimento mais direccionado para a sua actividade particular no contexto da sua empresa pública ou privada. O curso foi, durante o presente ano, apresentado já em quatro sessões, de Março a Julho, dado o interesse manifestado junto da direcção da FUNDEC. A coordenação organizou o programa do curso com uma componente prática, que se revelou uma das mais satisfatórias, e outra mais específica de forma a atender aos diversos interesses dos participantes. A assistência, no conjunto das diferentes sessões do curso, era composta por técnicos de formação distinta: engenheiros civis, mecânicos, electrotécnicos e informáticos, além de desenhadores, arquitectos e gestores. Por análise dos inquéritos recolhidos, o curso foi reconhecido com uma boa classificação global, assim, como os formadores convidados pelo coordenador, experientes no tema e com capacidade de comunicação, foram igualmente bem classificados. Ainda no presente ano, foi já agendada uma outra sessão do curso, para Novembro, devendo a coordenação introduzir alguma adaptação de conteúdos, de acordo com os aspectos sugeridos e incluídas nos inquéritos respondidos pelos participantes.

O principal objectivo do curso é essencialmente capacitar os participantes de treino e conhecimento que lhes seja útil na sua actividade. Os profissionais da indústria sentem necessidade de se actualizar no contexto BIM e o curso contribui de um modo positivo para essa aprendizagem. A escola e a indústria devem colaborar para um maior proveito de ambos.

\section{REFERÊNCIAS}

Araújo, L., 2016. Desenvolvimento de biblioteca de paredes na metodologia BIM, Dissertação de Mestrado em Construção, Instituto Superior Técnico, Universidade de Lisboa, Lisboa, Portugal.

Chen L.J. and Luo H., 2014. A BIM-based construction quality management model and its applications, Automation in Construction, 46 (2014) 64-73 http://dx.doi.org/10.1016/j.autcon.2014.05.009

Comissão Técnica (CT) 197 - Normalização BIM, 2017, https://www.tpf.pt/pt/comissao-tecnica-ct-197-normalizacaobim-c-1826-2----.html

Curso FUNDEC, 2019, Metodologia BIM na indústria da Construção, coordenação Sampaio, A.Z., http://www.fundec.pt/pt-pt/content/metodologia-bim-na-industria-da-construcao

Eadie R. et al, 2013. BIM implementation throughout the UK construction project lifecycle: An analysis, Automation in Construction, 36 (2013) 145-151. http://dx.doi.org/10.1016/j.autcon.2013.09.001

Eastman, C. et al, 2011. BIM Handbook: A guide to Building Information Modeling for owners, managers, designers, engineers, and contractors. $2^{\text {nd }}$ edition, John Wiley \& Sons, Inc., Hoboken, New Jersey, USA.

FUNDEC, 2019, Associação para a Formação e o Desenvolvimento em Engenharia Civil e Arquitectura http://www.fundec.pt/pt-pt/fundec

Sampaio, A.Z. and Berdeja, E., 2017. The use of BIM tools to support the development and analyses of projects, CUIEET 2017 - 25th International Congress in Innovation in Technical Education, Badajoz, Spain, pp. 577-586,

Sampaio, A.Z. and Mota C., 2016. BIM model of structures used in construction planning, Proceedings of the National meeting of Structural Concrete, Coimbra, Portugal, 10 pgs, http://be2016.dec.uc.pt/

Sampaio, A.Z. and Oliveira, J.D. 2019, BIM in structures: Analysis of interoperability, Proceedings of ICSAAM2019 - International Conference on Structural Analysis of Advanced Materials, Ischia, Italy, https://www.icsaamconference.com/index.php

Sampaio, A.Z., 2017. BIM as a Computer-Aided Design methodology in Civil Engineering, Journal of Software Engineering and Applications, Vol.10, No.02(2017), pp: 194-210, Article ID:74476,17 pages, 10.4236/jsea.2017.102012, https://doi.org/10.4236/jsea.2017, ISSN Online: 1945-3124, ISSN Print: 1945-3116

Sampaio, A.Z., 2018. Establishment of parametric objects to support multi BIM tasks, Proceedings of CINIE 2018 - $2^{\circ}$ Congreso Internacional de Innovación Educativa en Edificación, Madrid, Espanha, pp. 980 - 989.

Sampaio, A.Z., 2019. Education of the innovative BIM methodology claimed by the Construction industry, Proceedings of Agora - I Internacional sobre Educación, Investigación y Empleo, Badajoz, Espanha, www.agora2019.com

Serra, P., 2019. Aplicação da metodologia BIM em infra-estruturas, texto didáctico de módulo de curso FUNDEC: Metodologia BIM na indústria da Construção, Instituto Superior Técnico, Universidade de Lisboa, Lisboa, Portugal 